\begin{tabular}{|c|l|}
\hline Title & Global analysis of the pressure adjustment mechanism over sea surface temperature fronts using A IRS/A qua data \\
\hline Author(s) & Shimada, Teruhisa; Minobe, Shoshiro \\
\hline Citation & $\begin{array}{l}\text { Geophysical Research Letters, 38, LO66704 } \\
\text { https:/doi.org/_0.1029/2010GLO46625 }\end{array}$ \\
\hline Issue Date & 2011-03-30 \\
\hline Doc URL & http://hdl.handle.net/2115/47175 \\
\hline Rights & Copyright 2011 by the A merican Geophysical Union. \\
\hline Type & article \\
\hline File Information & GRL38_LO6704.pdf \\
\hline
\end{tabular}

Instructions for use 


\title{
Global analysis of the pressure adjustment mechanism over sea surface temperature fronts using AIRS/Aqua data
}

\author{
Teruhisa Shimada ${ }^{1}$ and Shoshiro Minobe ${ }^{2}$ \\ Received 29 December 2010; revised 1 February 2011; accepted 7 February 2011; published 30 March 2011.
}

[1] We investigate the signatures of atmospheric pressure adjustment mechanism for surface wind convergence/ divergence over major sea surface temperature (SST) frontal regions using global observations of satellite sounding and scatterometer. Lower tropospheric air thickness, which includes a sea-level pressure component modified by air temperature in the marine atmospheric boundary layer, is analyzed, and the relation between the Laplacian of the thickness and wind convergence are examined. Among four SST frontal regions in mid-latitudes, correlation between the thickness Laplacian and wind convergence is the largest over the Gulf Stream followed by those for the Agulhas Return Current and for the Brazil/Malvinas Current, and relatively small but still significant over the KuroshioOyashio Extension. These correlations strongly suggest that the pressure adjustment mechanism ubiquitously plays an important role in air-sea interaction over the global SST frontal regions. Furthermore, air temperatures in the first two regions exhibit SST-relating signatures even in the mid-troposphere. Citation: Shimada, T., and S. Minobe (2011), Global analysis of the pressure adjustment mechanism over sea surface temperature fronts using AIRS/Aqua data, Geophys. Res. Lett., 38, L06704, doi:10.1029/2010GL046625.

\section{Introduction}

[2] How ocean surface conditions influence the atmosphere is an important research subject for understanding of the Earth's climate. Scatterometer observations have revealed that surface wind divergence/convergence are strongly induced by sea surface temperature (SST) fronts associated with ocean currents (see reviews by Chelton et al. [2004], Xie [2004], and Small et al. [2008]). A well-known explanation for the wind response to SST fronts is the vertical mixing mechanism [e.g., Wallace et al., 1989]. The near-surface atmosphere destabilizes over warmer SSTs and the intensified vertical mixing brings large momentum from aloft to accelerate the surface wind. Microwave satellite observations of wind and SST have shown evidence of this mechanism globally: the Gulf Stream [e.g., Chelton et al., 2004], the Kuroshio Extension [e.g., Nonaka and Xie, 2003], the Brazil/Malvinas Currents [Tokinaga et al., 2005], and the Agulhas Return Current [e.g., O'Neill et al., 2005].

[3] Another mechanism is known as the pressure adjustment mechanism [e.g., Lindzen and Nigam, 1987; Feliks

\footnotetext{
${ }^{1}$ Center for Atmospheric and Oceanic Studies, Graduate School of Science, Tohoku University, Sendai, Japan.

${ }^{2}$ Department of Natural History Sciences, Graduate School of Science, Hokkaido University, Sapporo, Japan.

Copyright 2011 by the American Geophysical Union. 0094-8276/11/2010GL046625
}

et al., 2004]. In this mechanism, SST generates a difference of air temperature in the marine atmospheric boundary layer (MABL) across a front, and the resultant pressure anomalies produce wind convergence (divergence) over warm (cold) water. The importance of this mechanism has been mainly suggested by numerical studies over the Gulf Stream [e.g., Wai and Stage, 1989; Warner et al., 1990; Song et al., 2006] and over the tropical Pacific [Small et al., 2003, 2005]. Early observational studies that showed the importance of this mechanism used limited data such as sea level pressures (SLPs) observed at a few mooring buoys in the tropical Pacific [Cronin et al., 2003] or aircraft air-temperature observations across the Gulf Stream [Smahrt et al., 2004]. Recently, based on SLP data of high-resolution operational analyses, Minobe et al. [2008] proposed that this mechanism plays an important role in producing the observed pattern of wind convergence and divergence on the scale of the entire Gulf Stream. Furthermore, they suggested that the wind convergence over the Gulf Stream axis is important in determining the location of enhanced rain and tropospheric responses. Also, Tokinaga et al. [2009] and Minobe et al. [2010] found the minimum of spatially high-pass filtered SLPs collocated with the wind convergence over the Kuroshio Extension and the Gulf Stream, respectively, using a marine meteorological dataset. Thus, the pressure adjustment mechanism on the scale of ocean currents has attracted increasing attentions.

[4] However, no global investigation based on observations has been conducted for the pressure adjustment mechanism. The above-mentioned studies were analyses for a single frontal region based on different data and methods. In addition, no study has examined roles of this mechanism over frontal regions in the Southern Hemisphere such as the Brazil/Malvinas Current and the Agulhas Return Current. An observational analysis is required for the global climatological assessment of the pressure adjustment mechanism. To that end, a major difficulty arises from the fact that there is no global observational dataset of SLP which can resolve possible influences of oceanic fronts. However, unprecedented satellite sounding of air temperature, which successfully detected frontal influence on the atmosphere [ Liu et al., 2007], can be used for estimating SLP components modified by air temperatures in the MABL. The sounding data allow us to apply a newly-proposed method [Minobe et al., 2008] to assess the pressure adjustment mechanism globally. Therefore, this paper explores the pressure adjustment mechanism based on satellite observations including its geographical differences and seasonal variations.

\section{Data and Method}

[5] We use three datasets of satellite observations. Air temperatures are derived from Atmospheric Infrared Sounder 

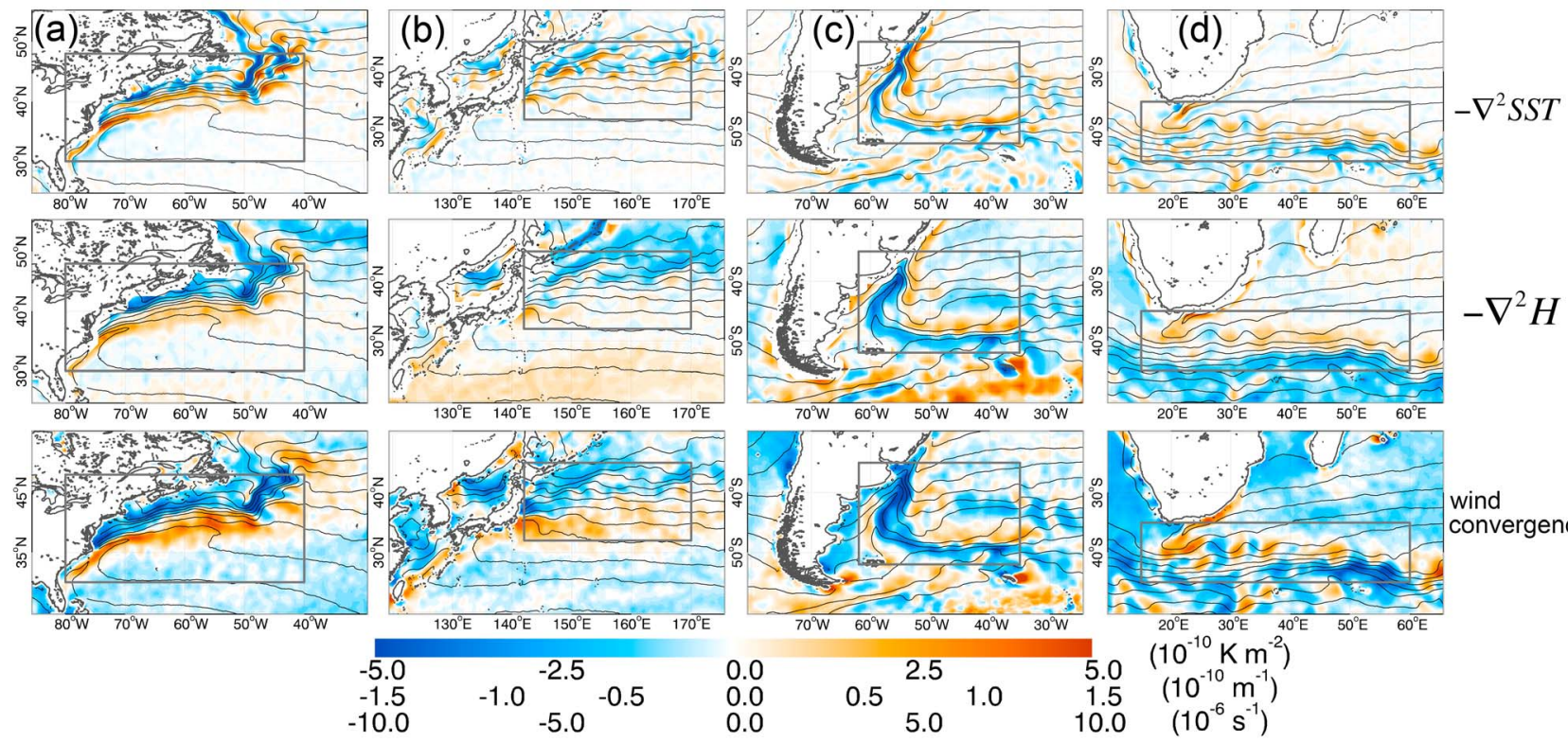

Figure 1. Annual mean fields of (top) SST Laplacian $\left(-\nabla^{2} S S T\right)$, (middle) thickness Laplacian $\left(-\nabla^{2} H\right.$ ), and (bottom) wind convergence for (a) the Gulf Stream, (b) the Kuroshio-Oyashio Extension, (c) the Brazil/Malvinas Current and (d) the Agulhas Return Current. The contours overlaid indicate SST at an interval of $2^{\circ} \mathrm{C}$. Framed rectangles indicate the areas in which data are sampled for the analyses in Figures 2 and 3. The measures of the color bar indicate the SST Laplacian, thickness Laplacian, and wind convergence from top to bottom.

(AIRS) onboard Aqua on a $1^{\circ} \times 1^{\circ}$ grid [e.g., Chahine et al., 2006]. Wind convergence is calculated from the equivalent neutral wind product from SeaWinds/QuikSCAT at a $0.25^{\circ} \times 0.25^{\circ}$ resolution. SST is obtained from Advanced Microwave Scanning Radiometer for Earth Observing System (AMSR-E) onboard Aqua at a $0.25^{\circ} \times 0.25^{\circ}$ grid. A Gaussian filter is applied to the respective data with an e-folding scale of $70 \mathrm{~km}$ to reduce noises primarily found in the AIRS data. This study analyzes climatological fields for 6 years (September 2002 to August 2008), and mainly focuses on the following four western boundary current regions in mid-latitudes: the Gulf Stream $\left(30^{\circ}-48^{\circ} \mathrm{N}\right.$, $\left.80^{\circ}-40^{\circ} \mathrm{W}\right)$; the Kuroshio-Oyashio Extension $\left(32^{\circ}-45^{\circ} \mathrm{N}\right.$, $\left.142^{\circ}-170^{\circ} \mathrm{E}\right)$; the Brazil/Malvinas Current $\left(52^{\circ}-35^{\circ} \mathrm{S}, 62^{\circ}-\right.$ $\left.35^{\circ} \mathrm{W}\right)$; and the Agulhas Return Current $\left(45^{\circ}-35^{\circ} \mathrm{S}, 15^{\circ}\right.$ $\left.60^{\circ} \mathrm{E}\right)$.

[6] We employ a method proposed by Minobe et al. [2008], who examined a linear relationship between the Laplacian of SLP and the near surface wind convergence as a measure of the pressure adjustment mechanism. Although the linear relation was based on a simple boundary layer model of Lindzen and Nigam [1987], its representativeness of the pressure adjustment mechanism was corroborated by a recent budget analysis using a regional atmospheric model over the western North Atlantic (K. Takatama et al., personal communication, 2010), and also by a striking similarity between the SLP Laplacian and wind convergence in a high-resolution air-sea coupled general circulation model $\left(0.1^{\circ}\right.$ for the ocean and $0.25^{\circ}$ for the atmosphere) over the Gulf Stream [Bryan et al., 2010].

[7] In order to examine the relation, we analyze a thickness $(H)$ between two isobaric levels of $1000\left(p_{1}\right)$ and $850\left(p_{2}\right) \mathrm{hPa}$ derived from the AIRS air-temperature observations. The thickness is defined as:

$$
H=\left(R_{d} / g\right) \int_{p_{2}}^{p_{1}} T d(\ln p),
$$

where $p$ is the air pressure, $g$ is the gravitational acceleration, $T$ is the air temperature, $R_{d}$ is the gas constant for dry air. The upper limit of $850 \mathrm{hPa}$ indicates that the layer includes the MABL within which the direct effect of SST variation is typically trapped [e.g., Minobe et al., 2008]. A larger thickness means a warmer air-temperature in the defined layer, which causes lower SLP. Thus, the thickness includes a SST-induced SLP variation, and the signreversed thickness Laplacian $\left(-\nabla^{2} H\right.$, hereinafter just thickness Laplacian) can be an alternative for the SLP Laplacian. The validity of the thickness Laplacian is confirmed by a significant linear relationship between the SLP Laplacian and thickness Laplacian both of which are computed from the European Centre for Medium-Range Weather (ECMWF) operational analysis data over the Gulf Stream (correlation is -0.74 for annual mean climatology of $0.5^{\circ}$ grid). Thus, spatial covariability between the thickness Laplacian and wind convergence, if found, can be evidence of the pressure adjustment mechanism. Also correspondence between the thickness Laplacian and sign-reversed SST Laplacian $\left(-\nabla^{2} S S T\right.$, hereinafter just SST Laplacian) indicates the importance of SST gradient for generating SLP differences across SST fronts.

\section{Results}

[8] Spatial coherences between the SST and thickness Laplacians and wind convergence are prominent in the four 

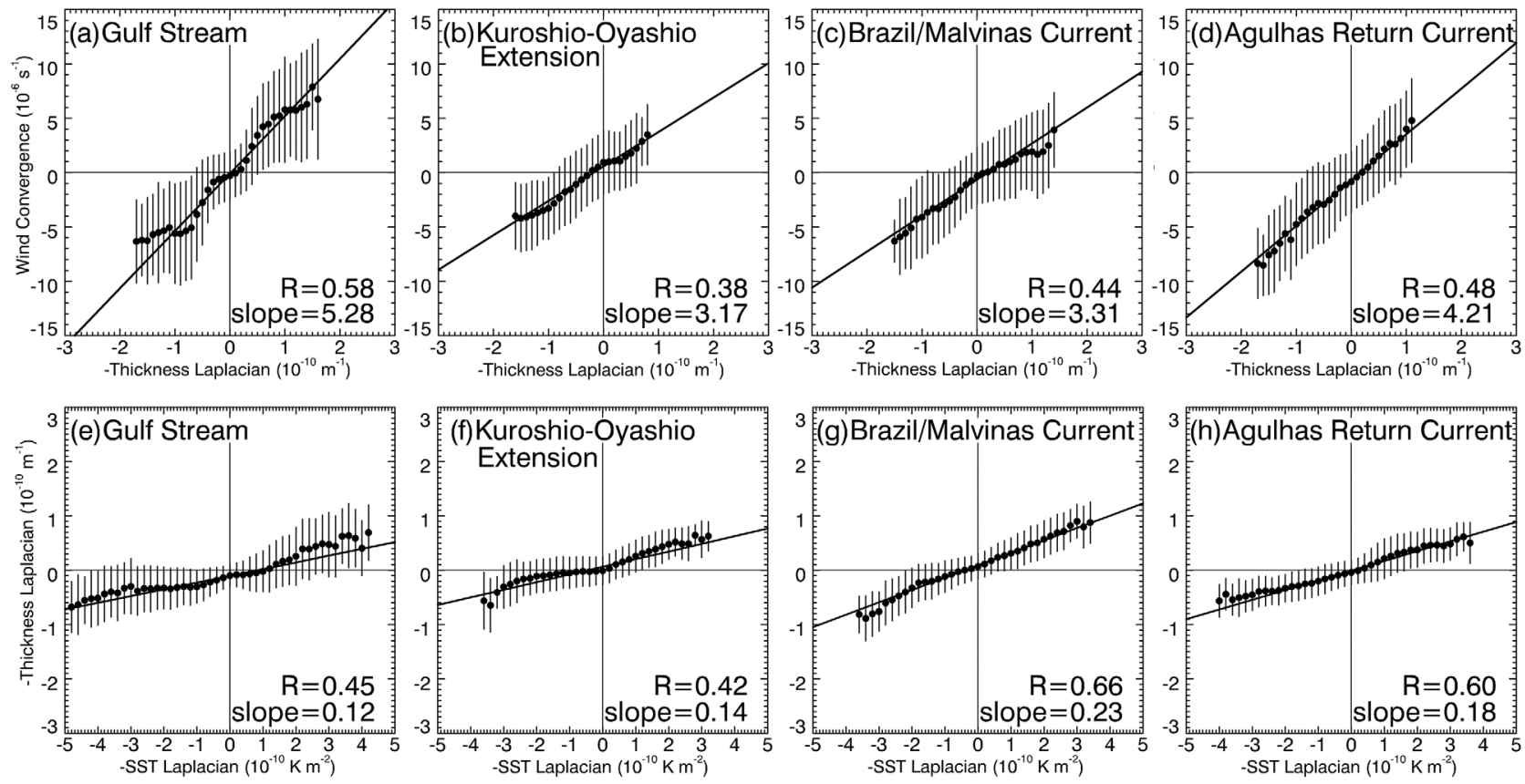

Figure 2. Annual relationships (top) between the thickness Laplacian and wind convergence and (bottom) between the SST and thickness Laplacians in the defined areas of (a, e) the Gulf Stream, (b, f) the Kuroshio-Oyashio Extension, (c, g) the Brazil/Malvinas Current and (d, h) the Agulhas Return Current based on monthly climatological data. The lines indicate regression lines with mean values (circles) and error bars ( \pm 1 standard deviation) of ordinate values for each bin of abscissa. Each panel includes a correlation coefficient $(\mathrm{R})$ and a slope of the regression line. When calculating the correlations in Figures $2 \mathrm{a}-2 \mathrm{~h}$ and $3 \mathrm{~b}$, the bins with the number of data less than 20 are excluded. The correlations are statistically significant or above $95 \%$ confidence level according to Student's $t$ test based on degrees of freedom derived from mean decorrelation (e-folding) scales $\left(\sim 1.0^{\circ}\right)$ in the defined areas.

frontal regions (Figure 1, for global maps see Figure S1). ${ }^{1}$ Furthermore, spatially high-pass filtered thickness shows similar patterns to the thickness Laplacian (Figure S2), confirming that the patterns do not depend on details of the methodology. Positive (negative) SST and thickness Laplacians and wind convergence (divergence) are distributed along the SST fronts on the warmer (colder) side on the whole. These correspondences are consistent with the pressure adjustment mechanism. Possible spatial shifts of $\sim 100-200 \mathrm{~km}$ between the parameters due to the mean wind advection [e.g., Small et al., 2003, 2005] are indiscernible here because of the low resolution of the AIRS data. Over the Gulf Stream (Figure 1a), the thickness Laplacian exhibits a strikingly similar pattern to the SLP Laplacian shown by Minobe et al. [2008]. Over the Kuroshio-Oyashio Extension (Figure 1b), the correspondences between the three parameters are generally weaker than those over the Gulf Stream. However, the positive SST and thickness Laplacians are collocated with the wind convergences on the south of the quasi-stationary axis of the Kuroshio Extension $\left(36^{\circ} \mathrm{N} / 143^{\circ}-150^{\circ} \mathrm{E}\right)$, consistent with Tokinaga et al. [2009]. Positive (negative) SST and thickness Laplacians are accompanied by wind convergence (divergence) to the south (north) of the subpolar fronts around $40^{\circ} \mathrm{N} / 152^{\circ} \mathrm{E}$. For the Brazil/Malvinas Current (Figure 1c), pairs of remarkable positive and negative bands of these three parameters extend along the SST fronts, say, meridionally along $54^{\circ} \mathrm{W}$ and

\footnotetext{
${ }^{1}$ Auxiliary materials are available in the HTML. doi:10.1029/ 2010GL046625.
}

zonally along $48^{\circ} \mathrm{S}$. Over the Agulhas Return Current and its meandering extension (Figure 1d), positive and negative values generally distribute north and south across the SST front along $42^{\circ} \mathrm{S}$, respectively. Consequently, the pressure adjustment mechanism plays a role in atmospheric responses over the major oceanic currents.

[9] In order to examine more closely the relations among the parameters, we draw scatter plots from the monthly

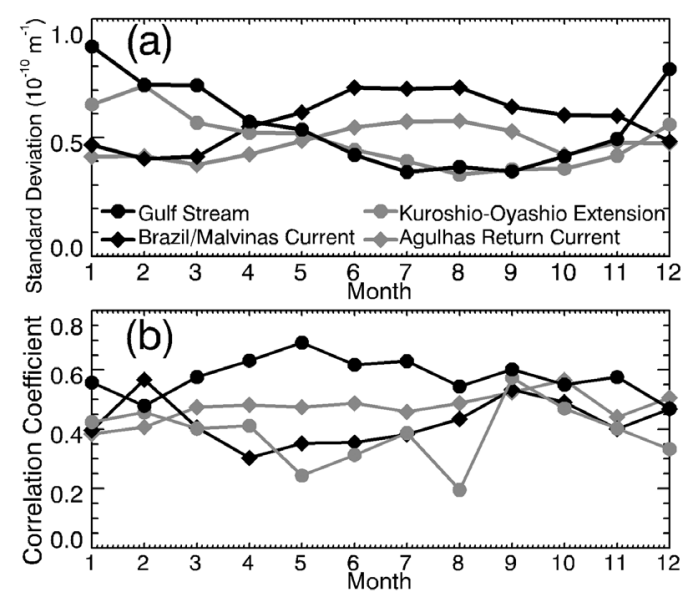

Figure 3. Monthly climatological variations of (a) standard deviation of the thickness Laplacian and (b) correlation coefficients between the thickness Laplacian and wind convergence. 
(a) Gulf Stream $\left(65-55^{\circ} \mathrm{W}\right)$

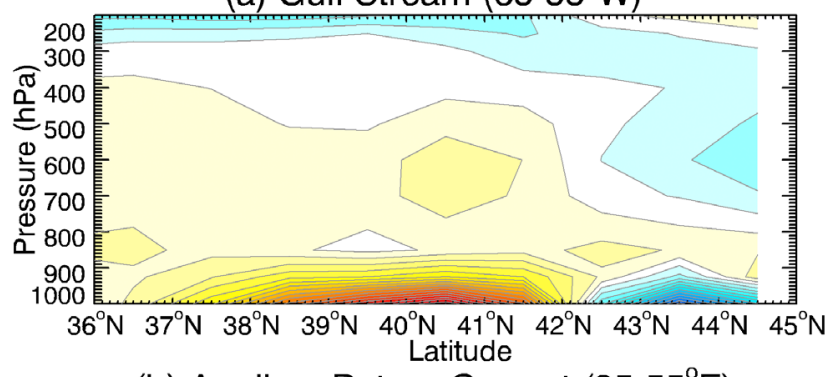

(b) Agulhas Return Current $\left(35-55^{\circ} \mathrm{E}\right)$

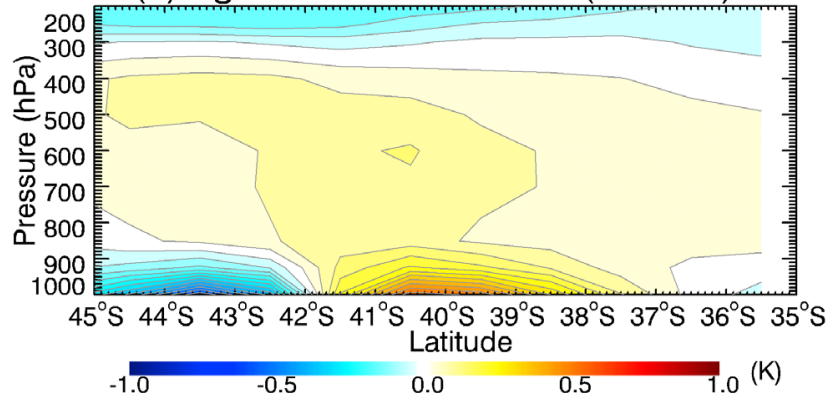

Figure 4. Vertical cross sections of high-pass filtered air temperature averaged annually and zonally over (a) the Gulf Stream $\left(65-55^{\circ} \mathrm{W}\right)$ and (b) the Agulhas Return Current $\left(35-55^{\circ} \mathrm{E}\right)$. Spatial high-pass filtered fields are derived by removing fields smoothed by $6^{\circ} \times 6^{\circ}$ averaging in latitude and longitude.

climatologies (Figure 2). In all the regions, clear linear relations are obtained with statistically significant correlation between the thickness Laplacian and wind convergence (Figure 2, top). The significant correlations show the contribution of the pressure adjustment mechanism to wind convergence, and the correlation coefficients and slopes may reflect regional differences of the contribution. The correlation coefficient is the highest for the Gulf Stream and the lowest for the Kuroshio-Oyashio Extension, suggesting that the pressure adjustment mechanism plays major and minor roles in the former and the latter regions, respectively. Meanwhile, linear relations between the SST and thickness Laplacians are evident in all the regions (Figure 2, bottom). These relations indicate that the pressure adjustment mechanism originates from the SST difference across the fronts.

[10] We look into the seasonal variations of the thickness Laplacian and its relation to wind convergence in the four regions. Figure 3a shows monthly climatological variations of spatial standard deviations of thickness Laplacian, as a measure of the amplitude of pressure perturbation. The standard deviations are larger (smaller) during the cool (warm) season in all the regions, suggesting that larger contrasts of surface heat flux across the SST fronts during the cool season contribute to yield larger pressure changes.

[11] In contrast, seasonal variations of the correlation coefficients between the thickness Laplacian and wind convergence are different from one region to another (Figure 3b). Over the Gulf Stream, the correlations are higher during the warm season as opposed to the smaller standard deviation (Figure 3a). In contrast, the correlations are generally higher during the cool season over the Kuroshio-Oyashio Exten- sion. The correlations show semi-annual variation for the Brazil/Malvinas Current, but relatively small seasonal variation over the Agulhas Return Current. These results indicate that other factors besides the SLP differences across the SST front are important for determining the degree of dominance of the pressure adjustment mechanism as discussed below.

[12] Another interesting question, which can be addressed using the AIRS data, arises whether or not air-temperature differences across the SST fronts penetrate to the free troposphere beyond the MABL. Increasing evidence indicates deep atmospheric responses to SST fronts in the midtroposphere [Liu et al., 2007; Kobashi et al., 2008; Minobe et al., 2008, 2010; Tokinaga et al., 2009]. We here examine vertical cross sections of spatially high-pass filtered airtemperature (see Figure S3 for global maps). As expected, signatures of the high-pass filtered air temperature coherent with the SST fronts are prominent between $1000-850 \mathrm{hPa}$ in the four analysis regions. However, its upward penetrations to the free atmosphere are apparent only over the Gulf Stream and the Agulhas Return Current, and the signatures extend up to $400 \mathrm{hPa}$ (Figure 4). Consequently, these AIRS air-temperature signatures corresponding to the SST fronts provide evidence of the SST front influence on the midtroposphere, in addition to the vertically upward winds found in operational analysis/reanalysis and satellite-derived cloud distributions [Minobe et al., 2008, 2010; Tokinaga et al., 2009]. Also, note that these signatures have length scale of 2,000-3,000 km along the SST fronts, in contrast to the smaller-scale tropospheric temperature anomalies of $\sim 300 \mathrm{~km}$ corresponding to the meanderings of the Agulhas Return Current [Liu et al., 2007].

\section{Discussion}

[13] What condition determines the importance of the pressure adjustment mechanism is still an open question. Spall [2007] shows that weaker winds crossing a SST front allow the pressure adjustment mechanism to develop. This suggests that when wind direction is parallel (perpendicular) to a SST front, the pressure adjustment mechanism plays a larger (smaller) role. Indeed, weak correlations are generally found for the Kuroshi-Oyashio Extension in boreal summer, when prevailing southerly winds cross the zonal SST fronts. Also, the small correlations occur for the Brazil/Malvinas Current in austral winter, when westerlies over the meridionally running SST front are strong. Over the Gulf Stream, winds are generally parallel to the SST front, probably contributing to the aforementioned strong correlation between the thickness Laplacian and wind convergence. For further investigations of the mechanism, it would be necessary to use regional or global atmospheric models [e.g., Small et al., 2005; Minobe et al., 2008; Kuwano-Yoshida et al., 2010; Bryan et al., 2010]. For a validation of those models, air-temperature observations by AIRS provide precious information.

[14] Acknowledgments. The QuikSCAT and AMSR-E data were downloaded from Remote Sensing Systems. The AIRS data were obtained from the NASA Goddard Earth Sciences Data Information and Services Center. The authors were supported by Grant-in-Aid for Scientific Research defrayed by the Ministry of Education, Culture, Sports, Science and Technology of Japan.

[15] The Editor thanks two anonymous reviewers. 


\section{References}

Bryan, F. O., R. Tomas, J. M. Dennis, D. B. Chelton, N. G. Loeb, and J. L. McClean (2010), Frontal scale air-sea interaction in high-resolution coupled climate models, J. Clim., 23, 6277-6291, doi:10.1175/ 2010JCLI3665.1.

Chahine, M. T., et al. (2006), AIRS: Improving weather forecasting and providing new data on greenhouse gases, Bull. Am. Meteorol. Soc., 87(7), 911-926, doi:10.1175/BAMS-87-7-911.

Chelton, D. B., M. G. Schlax, M. H. Freilich, and R. F. Milliff (2004), Satellite measurements reveal persistent small-scale features in ocean winds, Science, 303, 978-983, doi:10.1126/science.1091901.

Cronin, M. F., S.-P. Xie, and H. Hashizume (2003), Barometric pressure variations associated with eastern Pacific tropical instability waves, J. Clim., 16, 3050-3057, doi:10.1175/1520-0442(2003)016<3050: BPVAWE $>2.0 . \mathrm{CO} ; 2$.

Feliks, Y., M. Ghil, and E. Simonnet (2004), Low-frequency variability in the midlatitude atmosphere induced by an oceanic thermal front, J. Atmos. Sci., 61(9), 961-981, doi:10.1175/1520-0469(2004)061<0961: LVITMA $>2.0 . \mathrm{CO} ; 2$.

Kobashi, F., S.-P. Xie, N. Iwasaka, and T. T. Sakamoto (2008), Deep atmospheric response to the North Pacific oceanic subtropical front in spring, J. Clim., 21, 5960-5975, doi:10.1175/2008JCLI2311.1.

Kuwano-Yoshida, A., S. Minobe, and S.-P. Xie (2010), Precipitation response to the Gulf Stream in an atmospheric GCM, J. Clim., 23, 3676-3698, doi:10.1175/2010JCLI3261.1.

Lindzen, R. S., and S. Nigam (1987), On the role of sea surface temperature gradients in forcing low-level winds and convergence in the tropics, J. Atmos. Sci., 44(17), 2418-2436, doi:10.1175/1520-0469(1987) 044<2418:OTROSS $>2.0 . \mathrm{CO} ; 2$.

Liu, W. T., X. Xie, and P. P. Niiler (2007), Ocean-atmosphere interaction over Agulhas extension meanders, J. Clim., 20, 5784-5797, doi:10.1175/ 2007JCLI1732.1.

Minobe, S., A. Kuwano-Yoshida, N. Komori, S.-P. Xie, and R. J. Small (2008), Influence of the Gulf Stream on the troposphere, Nature, 452, 206-209, doi:10.1038/nature06690.

Minobe, S., M. Miyashita, A. Kuwano-Yoshida, H. Tokinaga, and S.-P. Xie (2010), Atmospheric response to the Gulf Stream: Seasonal variations, J. Clim., 23, 3699-3719, doi:10.1175/2010JCLI3359.1.

Nonaka, M., and S.-P. Xie (2003), Co-variations of sea surface temperature and wind over the Kuroshio and its extension: Evidence for oceanto-atmospheric feedback, J. Clim., 16, 1404-1413, doi:10.1175/15200442(2003)16<1404:COSSTA>2.0.CO;2.

O’Neill, L. W., D. B. Chelton, and S. K. Esbensen (2005), High-resolution satellite measurements of the atmospheric boundary layer response to SST variations along the Agulhas Return Current, J. Clim., 18, 27062723, doi:10.1175/JCLI3415.1.
Smahrt, L., D. Vickers, and E. Moore (2004), Flow adjustments across seasurface temperature changes, Boundary Layer Meteorol., 111, 553-564, doi:10.1023/B:BOUN.0000016600.63382.5f.

Small, R. J., S.-P. Xie, and Y. Wang (2003), Numerical simulation of atmospheric response to Pacific tropical instability waves, J. Clim., 16, 37233741, doi:10.1175/1520-0442(2003)016<3723:NSOART $>2.0 . C O ; 2$.

Small, R. J., S.-P. Xie, Y. Wang, S. K. Esbensen, and D. Vickers (2005), Numerical simulation of boundary layer structure and cross-equatorial flow in the eastern Pacific, J. Atmos. Sci., 62(6), 1812-1830, doi:10.1175/JAS3433.1.

Small, R. J., S. P. deSzoeke, S.-P. Xie, L. O’Neill, H. Seo, Q. Song, P. Cornillon, M. Spall, and S. Minobe (2008), Air-sea interaction over the ocean fronts and eddies, Dyn. Atmos. Oceans, 45, 274-319, doi:10.1016/j.dynatmoce.2008.01.001.

Song, Q., P. Cornillon, and T. Hara (2006), Surface wind response to oceanic fronts, J. Geophys. Res., 111, C12006, doi:10.1029/2006JC003680.

Spall, M. A. (2007), Midlatitude wind stress-sea surface temperature coupling in the vicinity of oceanic fronts, J. Clim., 20, 3785-3801, doi:10.1175/JCLI4234.1.

Tokinaga, H., Y. Tanimoto, and S.-P. Xie (2005), SST-induced surface wind variations over the Brazil-Malvinas Confluence: Satellite and in-situ observations, J. Clim., 18, 3470-3482, doi:10.1175/JCLI3485.1.

Tokinaga, H., Y. Tanimoto, S.-P. Xie, T. Sampe, H. Tomita, and H. Ichikawa (2009), Ocean frontal effects on the vertical development of clouds over the western North Pacific: In situ and satellite observations, J. Clim., 22, 4241-4260, doi:10.1175/2009JCLI2763.1.

Wai, M. M., and S. A. Stage (1989), Dynamical analyses of marine atmospheric boundary layer structure near the Gulf Stream oceanic front, Q. J. R. Meteorol. Soc., 115, 29-44, doi:10.1002/qj.49711548503.

Wallace, J. M., T. P. Mitchell, and C. Deser (1989), The influence of seasurface temperature on surface wind in the eastern equatorial Pacific: Seasonal and interannual variability, J. Clim., 2, 1492-1499, doi:10.1175/1520-0442(1989)002<1492:TIOSST>2.0.CO;2.

Warner, T. T., M. N. Lakhtakia, J. D. Doyle, and R. A. Pearson (1990), Marine atmospheric boundary layer circulations forced by Gulf Stream sea surface temperature gradients, Mon. Weather Rev., 118, 309-323, doi:10.1175/1520-0493(1990)118<0309:MABLCF>2.0.CO;2.

Xie, S.-P. (2004), Satellite observations of cool ocean-atmosphere interaction, Bull. Am. Meteorol. Soc., 85(2), 195-208, doi:10.1175/BAMS85-2-195.

S. Minobe, Department of Natural History Sciences, Graduate School of Science, Hokkaido University, Kita-10 Nishi-8 Kita-ku, Sapporo 0600810, Japan.

T. Shimada, Center for Atmospheric and Oceanic Studies, Graduate School of Science, Tohoku University, Aramaki Aza Aoba 6-3, Aoba-ku, Sendai, 980-8578, Japan. (shimada@ocean.caos.tohoku.ac.jp) 